
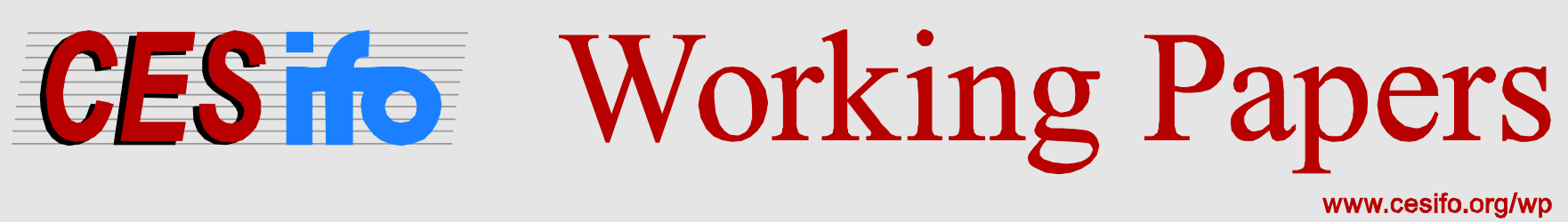

\title{
Inequality, Opting-out and Public Education Funding
}

\author{
Calin Arcalean \\ Ioana Schiopu
}

\author{
CESIFO WORKING PAPER NO. 5115 \\ CATEgory 2: Public CHOICE \\ DECEMBER 2014
}
An electronic version of the paper may be downloaded
- from the SSRN website:
- from the RePEc website:
- from the CESifo website:
wWw.SSRN.com
www.RePEc.org
www.CESifo-group.org/wp

\section{CESifo}




\title{
Inequality, Opting-out and Public Education Funding
}

\begin{abstract}
We investigate the relationship between inequality and political support for public education funding in a model of endogenous fertility and school choice. Household income heterogeneity is consistent with the skewness of empirical income distributions. Inequality can drive education spending in opposite directions in poor and rich economies. A mean preserving spread increases tax rates and public school enrollment, but decreases public spending per student in low income economies, while it has opposite effects at high income levels. An increase in the average income level can also have non-monotonic effects.
\end{abstract}

JEL-Code: D720, H420, I210, I220.

Keywords: education funding, inequality, political economy.

Calin Arcalean

Department of Economics, ESADE

Ramon Lhull University

Avenida de Torreblanca 59

08172 Sant Cugat del Vallès,

Barcelona / Spain

calin.arcalean@esade.edu
Ioana Schiopu*

Department of Economics, ESADE

Ramon Lhull University

Avenida de Torreblanca 59

08172 Sant Cugat del Vallès,

Barcelona / Spain

ioana.schiopu@esade.edu

*corresponding author

September 2014 


\section{Introduction}

Public provision of basic education is a major form of redistribution virtually everywhere. As income inequality is on the rise in most countries, investigating the repercussions for public education funding becomes a relevant issue given the particular role of human capital differences in perpetuating economic and social disparities. So far however, empirical work in the area has generated rather inconclusive results. ${ }^{1}$ This seems to warrant further theoretical efforts aimed at better understanding specific redistribution mechanisms.

We study a political economy model of public education provision with a private schooling option and endogenous fertility decisions. Importantly, we allow household income heterogeneity to be consistent with the skewness of empirical income distributions, where the median is lower than the mean income. Tax financed uniform public education quality is insufficient for rich parents who choose to send their children to a private school. This generates an endogenous income threshold that separates public and private school users. Ceteris paribus, the higher the public school quality, the lower the private enrollment share. Reflecting a quantity-quality trade-off, households opting for private education choose a lower fertility rate than those opting for public schooling. For transparency, fertility is constant within groups.

The equilibrium public spending arises as the politically mediated balance between the conflicting interests of public and private school users. On the one hand, those opting for private schooling want to minimize the tax burden. On the other hand, those who choose public schooling, want to ensure adequate spending per student. In this setting we study how the political balance and thus the equilibrium education spending and enrollment respond in two counterfactual experiments: a) a mean preserving spread of the income distribution and b) an increase in the tax base keeping income dispersion constant.

First, we show that inequality can drive education spending in opposite directions in poor and rich economies. A mean preserving spread increases tax rates (spending per capita) and public school enrollment, but decreases public spending per student in low income economies, while it has opposite effects at high income levels. A marginal increase in the tax base, holding income dispersion constant, can also have non-monotonic effects. Furthermore, tax base and inequality effects on redistribution depend critically on the parental preferences for quality versus quantity of children.

When inequality increases, the tails of the income distribution (the poor and rich

\footnotetext{
${ }^{1} \mathrm{~A}$ number of papers have found that support for redistribution is weaker in more unequal or more heterogenous societies (Goldin and Katz (1997), Alesina et al. (1999, 2001), Lindert (1996), Luttmer (2001)). Perotti (1996) finds no relationship between inequality and redistribution in democracies. More recently, Boustan et al. (2010) find that rising inequality in cities and school districts is associated with higher local revenue collection and expenditures.
} 
groups) get larger, while the middle income group shrinks. In a poor economy where fertility rates are high and/or the tax base is low, public schools are of low quality, so a large share of the middle income households use private schools (the endogenous income threshold is far from the tail). A mean preserving spread produces a replacement of these families by high fertility low income families that choose public education. This shift in school choice dominates the negative effect on redistribution generated by a larger rich group. Consequently, the interests of the poor dominate and thus the support for public education increases. However, the endogenous enrollment in public school rises at a faster rate than resources, depressing spending per student. In contrast, when the tax base is high, like in a rich economy, most households from the middle group use public education (the indifference income threshold is close to the tail). The replacement of families from the middle group by poor ones does not produce a large positive effect on the support for redistribution as the two groups have the same school choice. Thus the larger rich income group steers the political process in their favor, lowering the tax rate and spending on public education. However, the overall public spending per student increases as resources decrease at a lower rate than the endogenous enrollment.

As a benchmark, we focus on probabilistic voting with households that have uniform political power. Asymmetric distribution of political power is typically associated with authoritarian regimes or partially democratic countries. However, it can also arise in well established democracies if, as documented by the literature on political participation, voter turnout varies systematically with demographic characteristics. We extend the model to include an income based index of political power and study its properties. The effects on per student spending and enrollment in public schools are preserved under an empirically relevant degree of political power. In contrast to the benchmark model however, the tax rate can decrease in the poor economies when inequality decreases, depressing the public spending per student even further.

The results are significant in at least three dimensions. First, we conceptually decompose inequality variation into a tax base change and a pure income dispersion effect and explain the non-trivial role each component plays in determining public spending for education and enrollment in public schools. Second, the theoretical analysis helps illuminate empirical work. On the one hand, the non-monotonic response of redistribution in our framework may justify some of the conflicting results obtained so far in the literature. On the other hand, and more importantly, we provide an alternative framework to think about differences in redistribution through public education. For example, while typical regressions include the median income, our theory suggests controlling for the mean income both directly and through its interactions with dispersion measures. Finally, our results imply a novel mechanism of inequality amplification arising through the endogenous determination of public education spending. To the extent spending per student is important for human capital formation, and thus, future income, diverging 
public education funding at different mean income levels can widen the initial income disparities.

\subsection{Connections to the literature}

Our paper contributes to the theoretical literature studying the effects of inequality on public goods provision and income redistribution. While some political economy papers argue that higher inequality leads to more redistribution through higher taxation (Meltzer and Richard (1981), Persson and Tabellini (1994), Bénabou (1997)), others find that more unequal or more heterogenous societies spend less on public goods (Soares (1998), de la Croix and Doepke (2009)). Glomm (2004) finds that the relationship between inequality and the amount of redistribution through public education services depends on the elasticity of substitution between consumption and the quality of education in the parent's utility. He finds that for empirically relevant value of this parameter, higher inequality generates less redistribution.

Bénabou (1997, 2000) and Lee and Roemer (1998) focus on capital market imperfections to show that non-monotonic responses of redistribution to inequality are possible. Fernandez and Levy (2008) also find a non-monotonic effect of increased diversity in a model with income and preference heterogeneity. Complementary to these studies, we obtain a non-monotonic effect of inequality on redistribution at different levels of the average income per capita stemming from endogenous fertility and education choices. Also, in these papers, redistribution occurs through progressive taxation (Bénabou (2000)) or the provision of universal public education (Lee and Roemer (1998)). In the latter case, private and public investments in education are complements, but only the rich households top up. In contrast, we focus on public education funding when the rich can opt out of the public system.

While our framework is similar to de la Croix and Doepke (2009), there are several important differences. First, we allow for a more empirically relevant income distribution. In equilibrium the asymmetric weights of rich and poor households interact with schooling and fertility decisions in novel and interesting ways. In particular, we show the effects of income dispersion on spending and enrollment in public schools are modulated by the mean income level in the economy. Second, we complement our analysis of inequality by looking at the distinct effects of tax base changes on redistribution through public education. Third, we introduce a parsimonious and tractable index of political power that derives naturally from the underlying income distribution and has a straightforward data counterpart. Moreover, in our framework a unique equilibrium always exists for empirically relevant values of the political power parameter.

In contrast to models that study how sorting across communities affects public goods 
provision and inequality ${ }^{2}$, in this paper we study how education funding responds to exogenous changes in inequality. At first, this feature may seem to circumscribe our analysis to large political units such as countries or states in a federation. However, to the extent income inequality is driven by national or global factors (e.g. skill biased technological change, international trade) rather then by sorting incentives, our model applies equally well to smaller political units, such as municipalities or school districts. ${ }^{3}$

The remainder of the paper is structured as follows. Section 2 presents the model. Section 3 defines the equilibrium and derives the main analytical results. Section 4 documents significant participation differences in local politics related to public education provision and extends the benchmark model by incorporating political power. Section 5 concludes. Proofs are relegated to Appendix A. Additional material is provided in Appendix B.

\section{The model}

The economy is populated by a large number of households, which are heterogenous in income. The mass of households is normalized to one. Each household consists of an adult and a number of children. Children are educated either in public schools, which are financed by a consumption tax, or in private schools, financed by parental spending. Household income is distributed according to a Pareto distribution, with p.d.f. $f$ and c.d.f. $F$, with parameters $y_{l}>0$ and $\alpha>2$, and support $y \in\left[y_{l} ; \infty\right) .{ }^{4}$ The mean and standard deviation of the income distribution are given by:

$$
\mu=\frac{\alpha}{\alpha-1} y_{l} \text { and } \sigma=\frac{y_{l}}{\alpha-1} \sqrt{\frac{\alpha}{\alpha-2}}
$$

Adults derive utility from net of tax consumption $c$, the number of children $n$ and the quality of their education $E$, which can be private or public. Private education has a unit price. Let $q$ denote the quality of public schools. Households can opt out of publicly provided education and send their children to a private school of quality $e^{r}$. The

\footnotetext{
${ }^{2}$ See, for example, Epple et al. (1993), Epple and Platt (1998), Bénabou (1994), Bénabou (1996), Fernandez and Rogerson (1996), Bearse et al. (2001).

${ }^{3}$ Recent empirical studies (e.g. Cutler et al. (1999), Rhode and Strumpf (2003) and Baicker et al. (2012)) have shown that even in the United States, the textbook example of Tiebout sorting, segregation across communities has been constant or even declined, suggesting that the rise in income inequality across districts, MSAs or states in recent decades cannot be explained by Tiebout sorting alone.

${ }^{4}$ The p.d.f. is given by $f(y)=\alpha y_{l}^{\alpha} / y^{\alpha+1}$, for $y>y_{l}$ and zero otherwise. The c.d.f. is $F(y)=$ $1-\left(y_{l} / y\right)^{\alpha}$. The Pareto distribution is used for tractability reasons (see also Lee and Roemer (1998)). Other distributions used in the literature yield similar qualitative results. As a robustness check, in Appendix B we replicate the main results numerically using a log-normal income distribution.
} 
preferences are given by:

$$
u(c, n, E)=\ln (c)+\gamma[\ln (n)+\theta \ln (E)],
$$

where $E=q, e^{r}, \gamma>0$ and $\theta \in(0,1) .{ }^{5}$ Besides providing tractability, the assumption of logarithmic utility is consistent with the empirical evidence, which suggests that income and substitution elasticities of education spending have similar magnitudes. ${ }^{6}$

The government taxes the consumption of all households at the constant rate $\tau$. Tax revenues are used to finance public education of uniform quality for all children. For simplicity, we assume that quality of schooling is equal to the spending per student. The public policy is determined through a probabilistic voting mechanism described below. Besides being tractable, this mechanism formalizes in a general way preference aggregation in local education politics.

Private choices on fertility and education are made before voting on the quality of public education takes place. Agents have perfect foresight regarding the outcome of the voting process. Thus, in equilibrium, the expected spending per student in public education equals the level chosen by voting.

This timing reflects the sizeable differences in the relative costs and time horizons of the decisions involved. While public education spending is usually decided through yearly budget votes, fertility and child rearing decisions cannot be easily adjusted at this frequency and depend largely on "pre-determined" characteristics, such as income, education level, race, religion, etc. A similar argument applies to the choice between public and private schooling, which in the U.S. is tightly connected to residential choice and therefore can entail substantial switching costs. ${ }^{7}$

Furthermore, notice that under perfect foresight, a quantity-quality trade-off maps fertility decisions into consistent school choices. Therefore, even if households decide on private vs. public education after policies are set, as long as fertility decisions occur before the vote on public education quality, the same equilibrium will obtain as under the original timing. ${ }^{8}$

\footnotetext{
${ }^{5}$ As we explain later, private decisions are taken before public policy is implemented. This implies that housholds have to form expectations over policy variables, such as the quality of public education, $q$. Since we assume perfect foresight, and in order to avoid clutter, we use the same notation for expected and realized values of a variable.

${ }^{6}$ See Gradstein et al. (2005), pg. 50-51 for a discussion.

${ }^{7}$ de la Croix and Doepke (2009) also conclude that in countries where the educational and residential segregation are correlated, private decisions generate strong lock-in effects. Thus, in the case of the U.S. school districts, the focus of our empirical analysis, having households make their decisions before the policy is chosen seems the most appropriate assumption.

${ }^{8}$ See Dottori and Shen (2009) for a related discussion.
} 


\subsection{Household's problem}

Household consumption can be interpreted in this framework as housing services and is subject to a constant tax rate $\tau$. As we show later, this assumption implies that the decisions regarding the quantity and quality of children are not affected by taxation. Furthermore, in this case endogenous fertility generates a constant tax base in equilibrium, which does not depend on the aggregate enrollment in public education. ${ }^{9}$

Rearing children involves a time cost. Denote by $\phi \in(0,1)$ the fraction of the parent's time spent raising a child, and with $U^{p}$ and $U^{r}$ the utility of households whose children are educated in the public and private schools, respectively. Given the expected quality of publicly provided education $q$ and the tax rate $\tau$, a household with income $y$ that chooses public education solves the following problem:

$$
\begin{aligned}
\max _{\{c \geq 0, n \geq 0\}} U^{p}(c, n, q) & =\ln (c)+\gamma \ln (n)+\gamma \theta \ln (q), \\
\text { s.t. } c(1+\tau) & \leq y(1-\phi n) .
\end{aligned}
$$

The solution of problem (3) is $n^{p}=\gamma /[\phi(1+\gamma)]$.

On the other hand, a household choosing private education solves:

$$
\begin{aligned}
\max _{\left\{c \geq 0, n \geq 0, e^{r} \geq 0\right\}} U^{r}\left(c, n, e^{r}\right) & =\ln (c)+\gamma \ln (n)+\gamma \theta \ln \left(e^{r}\right), \\
\text { s.t. } c(1+\tau)+n e^{r} & \leq y(1-\phi n) .
\end{aligned}
$$

The solutions to the problem (5) are $n^{r}=[\gamma(1-\theta)] /[\phi(1+\gamma)]$ and $e^{r}=\phi \theta y /(1-\theta)$. Comparing $n^{p}$ and $n^{r}$ we see that households that choose private schooling have a lower fertility than those sending the children to public schools. Also note that consumption for both household types is a constant share of income $c=y /((1+\gamma)(1+\tau))$.

Substituting $n^{p}$ in (3) and $n^{r}$ and $e^{r}$ in (5) we obtain the indirect utilities of households that choose public and private schooling, respectively:

$$
V^{p}(y, q)=\ln \left[\frac{y}{(1+\gamma)(1+\tau)}\right]+\gamma \ln \left[\frac{\gamma}{\phi(1+\gamma)}\right]+\gamma \theta \ln (q)
$$

and

$$
V^{r}(y)=\ln \left[\frac{y}{(1+\gamma)(1+\tau)}\right]+\gamma \ln \left[\frac{\gamma(1-\theta)}{\phi(1+\gamma)}\right]+\gamma \theta \ln \left[\frac{\phi \theta y}{1-\theta}\right] .
$$

A household will choose public education if and only if $V^{p}(y, q) \geq V^{r}(y)$. This inequality is satisfied for households with income lower than a threshold $\widetilde{y}$, given by:

$$
\widetilde{y}=\frac{q}{\phi \theta \delta}, \text { where } \delta=(1-\theta)^{\frac{1}{\theta}-1} \in(0,1)
$$

\footnotetext{
${ }^{9}$ de la Croix and Doepke (2009) obtain similar results assuming an income tax and tax deductibility of private education spending.
} 
Households choose the school type taking the other households' decisions as given. Denote by $\Psi$ the fraction of households that choose public schooling. In equilibrium, the individual choices must be consistent with the aggregate outcome, that is, the share of households with income lower than the threshold $\widetilde{y}$ should be equal to $\Psi$. The consistency condition is:

$$
\Psi(q)=F(\widetilde{y}(q))=\int_{y_{l}}^{\widetilde{y}(q)} f(y) d y=1-\left(\frac{y_{l}}{\widetilde{y}(q)}\right)^{\alpha} .
$$

An alternative way to state this rationality condition is that the expected quality of public education equals the implemented level: $E(q)=q$.

Notice that $\Psi(q)$ is not equal to the fraction of children that go to public schools since the model incorporates fertility decisions. Thus, the fraction of children in public schools is given by:

$$
N(q)=\frac{n^{p} \Psi(q)}{n^{p} \Psi(q)+n^{r}(1-\Psi(q))} .
$$

Substituting the expressions for $n^{p}$ and $n^{r}$ we obtain:

$$
N(q)=\frac{\Psi(q)}{(1-\theta)+\theta \Psi(q)}>\Psi(q)
$$

\subsection{Government budget constraint}

The government budget is balanced:

$$
\int_{y_{l}}^{\widetilde{y}} q n^{p} f(y) d y=\tau \int_{y_{l}}^{\infty} \frac{y}{(1+\gamma)(1+\tau)} f(y) d y,
$$

where the left-hand side is the total public education spending, and the right-hand side the collected tax revenues from both types of households (public and private school users, respectively). The right-hand side of (13) shows clearly that the fraction of income that is taxable is constant across income groups and is equal to $1 /((1+\gamma)(1+\tau))$. As a result, the total tax base is constant and does not depend on the fraction of households choosing private schooling. Integrating over the support of the distribution, the right-hand side of the government budget constraint becomes $\tau \mu /((1+\gamma)(1+\tau))$, where $\mu=\int_{y_{l}}^{\infty} y f(y) d y$ is the average income and also the tax base. Using the expression for $n^{p}$ in the lefthand side, we can express the quality of public schooling as a function of the fraction of households that choose public schools, $\Psi$, and the tax rate, $\tau$ :

$$
q \Psi(q) \frac{\gamma}{\phi}=\frac{\tau \mu}{1+\tau}
$$




\subsection{Voting on public education funding}

The public policies are determined through probabilistic voting. The voting problem is unidimensional, i.e. once the tax rate is chosen, the spending per student $q$ is determined from (14). Consider a set-up with two political parties, each proposing a program. Voters care about the education policy proposed but also about a second dimension of the electoral platform, called "ideology". The probability that an individual votes for a party thus depends on her ideological bias toward the party's proposed platform. The results of the elections are a random event, each party having a probability of winning.

The ideological preferences are assumed to be orthogonal to those on public policy. Thus, the probability that a person votes for a certain party (and the party vote share) is a smooth function of the distance between the two platforms. This framework has a unique equilibrium in which both parties converge to the same platform (see Persson and Tabellini (2002)), which maximizes the following social welfare function:

$$
W(\tau)=\int_{y_{l}}^{\widetilde{y}} U^{P}\left(y, n^{p}, q, \tau\right) p(y) f(y) d y+\int_{\widetilde{y}}^{\infty} U^{R}\left(y, n^{r}, e^{r}, \tau\right) p(y) f(y) d y
$$

subject to the government budget constraint (14).

The first and second terms of the welfare function are the aggregate utilities of the households that choose public and private education, respectively. The term $p(y)$ captures the political power of the group. We first assume $p(y)=1$, that is, all voters have the same political power. We relax this assumption in section 4 .

Note that the income threshold $\widetilde{y}$ is taken as given in the maximization, in keeping with the assumption that fertility and education choices are predetermined when the vote takes place. While making the analysis more tractable, this assumption is still consistent, in equilibrium, with perfect foresight: the expected and the actual shares of households that choose public schooling are equal.

Substituting the indirect utility functions, (7) and (8), in (15) and grouping terms, we get:

$$
\begin{gathered}
W(\tau)=\ln \left(\frac{1}{(1+\gamma)(1+\tau)}\right)+\gamma \ln \left[\frac{\gamma}{\phi(1+\gamma)}\right]+\gamma \theta \ln (q(\tau)) \int_{y_{l}}^{\widetilde{y}} f(y) d y+ \\
\int_{\widetilde{y}}^{\infty}\left\{\gamma \ln (1-\theta)+\gamma \theta \ln \left[\frac{\phi \theta y}{1-\theta}\right]\right\} f(y) d y .
\end{gathered}
$$

Since only the first and the third term are functions of the policy variables, the welfare can be rewritten (with abuse of notation) as

$$
W(\tau)=-\ln (1+\tau)+\gamma \theta \Psi \ln (q(\tau))
$$

where $\Psi(\widetilde{y})$ is taken as given. Substituting $q$ from (14) and taking the first order condition 
with respect to $\tau$ yields:

$$
\tau=\gamma \theta \Psi
$$

Everything else equal, the tax increases with the households' concern for children as well as with the fraction of households using public education. In the next section we define the equilibrium and study its properties.

\section{$3 \quad$ Equilibrium analysis}

Definition 1. A politico-economic equilibrium is an income threshold $\widetilde{y}$ satisfying (9), private allocations $\left(c^{p}, n^{p}\right)$ if $y \leq \widetilde{y},\left(c^{r}, n^{r}, e^{r}\right)$ if $y>\widetilde{y}$, and a public policy $(q, \tau)$ such that:

(i) household's decisions solve problems (3) or (5), given public policy $(q, \tau)$;

(ii) the government budget is balanced, i.e. it satisfies (14);

(iii) the tax rate $\tau$ solves the social welfare maximization problem (15);

(iv) the consistency condition (10) is satisfied.

Next, we solve for the equilibrium threshold $\widetilde{y}$. To minimize clutter, we drop functional dependencies where possible. We use the expression of $q,(14)$, and $\tau,(17)$ in (9) to obtain:

$$
\widetilde{y}=\frac{\mu}{\delta} \frac{1}{1+\gamma \theta \Psi(\widetilde{y})} .
$$

Using the consistency condition, (10) yields the following expression in $\widetilde{y}$ :

$$
\widetilde{y}=\frac{\mu}{\delta} \frac{1}{1+\gamma \theta\left[1-\left(\frac{y_{l}}{\widetilde{y}}\right)^{\alpha}\right]} .
$$

Proposition 1. There exists a unique and interior equilibrium income threshold $\widetilde{y}^{*} \in$ $\left(y_{l}, \infty\right)$ that solves equation (19) (proof in the Appendix).

Note that the equilibrium threshold $\widetilde{y}^{*}$ is always interior because the support of the income distribution does not have an upper bound. When $\widetilde{y}^{*} \rightarrow \infty$, the fraction of students in public schools goes asymptotically to 1 . Equilibrium uniqueness also owes to the endogenous fertility, which ensures that the tax base is independent of public education enrollment and thus the right hand side of equation (19) is decreasing in $\Psi$.

Proposition 1 implies there is a unique equilibrium public spending per student:

$$
q^{*}=\widetilde{y}^{*} \phi \theta \delta=\frac{\phi \theta \mu}{1+\gamma \theta\left[1-\left(\frac{y_{l}}{\widetilde{y}^{*}}\right)^{\alpha}\right]} .
$$


We use equations (10) and (20) to express $\Psi^{*}$ as a function of $q^{*}$ :

$$
\Psi^{*}=\frac{1}{\gamma \theta}\left(\frac{\phi \theta \mu}{q^{*}}-1\right)
$$

Using (10) in (12), we obtain the equilibrium enrollment in public schools:

$$
N^{*}=\frac{\Psi^{*}}{(1-\theta)+\theta \Psi^{*}}, \text { where } \Psi^{*}=1-\left(\frac{y_{l}}{\widetilde{y}^{*}}\right)^{\alpha} .
$$

In the following, we investigate how changes in the income distribution affect the main policy variables. We focus on two experiments: a) a change in the average income per capita $\mu$, keeping the standard deviation $\sigma$ constant and b) a mean preserving spread in the income distribution (change $\sigma$ while keeping $\mu$ constant).

\subsection{A change in the mean income (tax base)}

Now we analyze the effects of changing the mean income, $\mu$, on the equilibrium public spending per student $q^{*}$, the tax rate $\tau^{*}$, and enrollment in public schools $N^{*}$. Recall that in our model $\mu$ also represents the tax base.

Denote by $d(\mu, \sigma)=\left[y_{l}(\mu, \sigma) / \widetilde{y}(\mu, \sigma)\right]^{\alpha(\mu, \sigma)}$. The derivative of $N^{*}$ with respect to $\mu$ is:

$$
\begin{aligned}
\frac{\partial N^{*}}{\partial \mu} & =\frac{1-\theta}{\left[(1-\theta)+\theta \Psi^{*}\right]^{2}} \frac{\partial \Psi^{*}}{\partial \mu} \\
& =\frac{1-\theta}{\left[(1-\theta)+\theta \Psi^{*}\right]^{2}} \frac{\phi}{\gamma} \frac{q^{*}-\mu \frac{\partial q^{*}}{\partial \mu}}{\left(q^{*}\right)^{2}}
\end{aligned}
$$

where

$$
\frac{\partial q^{*}}{\partial \mu}=\frac{\phi \theta\left\{1+\gamma \theta(1-d)+\mu \gamma \theta \frac{\partial d(\mu, \sigma)}{\partial \mu}\right\}}{[1+\gamma \theta(1-d)]^{2}} .
$$

Using (17) and (21) we obtain the change in the equilibrium tax rate with respect to $\mu:$

$$
\frac{\partial \tau^{*}}{\partial \mu}=\gamma \theta \frac{\partial \Psi^{*}}{\partial \mu}
$$

Thus, $\operatorname{sign}\left(\partial \tau^{*} / \partial \mu\right)=\operatorname{sign}\left(\partial \Psi^{*} / \partial \mu\right)=\operatorname{sign}\left(\partial N^{*} / \partial \mu\right)$. Studying the properties of the function $\partial N^{*} / \partial \mu$ yields the following results.

Proposition 2. Let $\underline{\gamma}=[(2 /(\delta e))-1] /\left\{\theta\left[1-e^{-2}\right]\right\}$ and $\bar{\gamma}=[(1 / \delta)-1] /\{\theta[1-(1 / e)]\}$, where $e$ is the Euler's constant.

1) If $\gamma \leqslant \underline{\gamma}$, then $\partial N^{*} / \partial \mu>0$ and $\partial \tau^{*} / \partial \mu>0$;

2) If $\gamma \geqslant \bar{\gamma}$, then $\partial N^{*} / \partial \mu<0$ and $\partial \tau^{*} / \partial \mu<0$;

3) If $\gamma \in(\underline{\gamma}, \bar{\gamma})$, then there exist a unique $\widehat{\mu} \in(0, \infty)$ such that 
3.1) if $\mu \in(0, \widehat{\mu}]$, then $\partial N^{*} / \partial \mu \leqslant 0$ and $\partial \tau^{*} / \partial \mu \leqslant 0$;

3.2) if $\mu \in(\widehat{\mu}, \infty)$, then $\partial N^{*} / \partial \mu>0$ and $\partial \tau^{*} / \partial \mu>0$;

(Proof in the Appendix).

The next corollary establishes sufficient conditions under which the equilibrium spending per student $q^{*}$ varies positively with the mean income.

Corollary 1. 1) If $\gamma \geqslant \bar{\gamma}$, then $\partial q^{*} / \partial \mu>0$;

2) If $\gamma \in(\underline{\gamma}, \bar{\gamma})$ there exists $\widetilde{\mu}>\widehat{\mu}$ such that $\partial q^{*} / \partial \mu>0$ on the interval $\mu \in(0, \widetilde{\mu})$ (Proof in the Appendix).
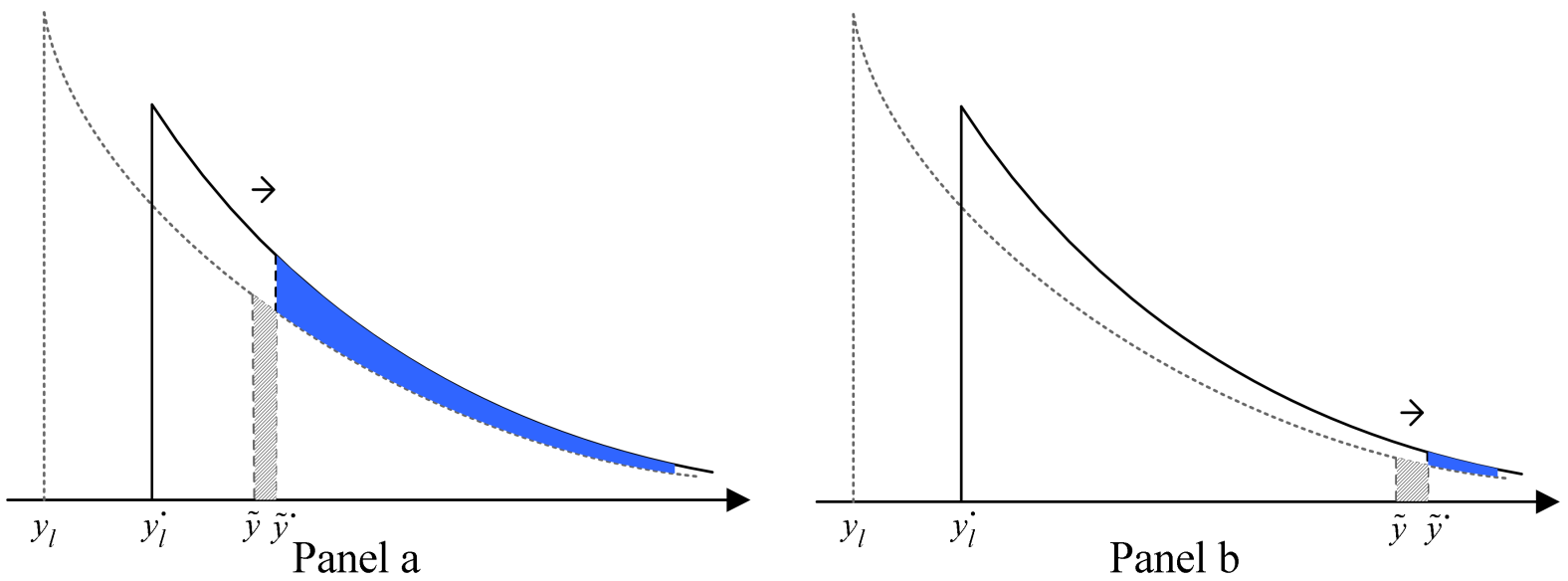

Figure 1: An increase in the tax base (mean income per capita), indicated by dot variables (e.g. $\mu^{\bullet}>\mu$ ) and solid lines. Panel a: high fertility preference $(\gamma)$ or low tax base $(\mu)$. Panel b: low fertility preference or high tax base. The arrow indicates the endogenous change in the indifference threshold. Dark (light) shaded areas represent increases (decreases) in the support for private education.

As it is apparent from Proposition 2, the effects of an increase in the tax base depend on $\gamma$. Equilibrium fertility allocations $n^{p}$ and $n^{r}$ are increasing functions of $\gamma$, while private education spending $e^{r}$ does not depend on $\gamma \cdot{ }^{10}$ We therefore interpret $\gamma$ as a relative weight of fertility in the parental preferences.

Everything else equal, a marginal increase in the tax base keeping dispersion constant has two effects. As $y_{l}$ increases, the right tail of the income distribution becomes thicker. The increase in the mass of relatively richer households has a positive effect on the demand for private education. Call this the (exogenous) shape effect. Second, it increases the resources available for public education. This makes the households that were previously indifferent between private and public education always choose the latter. Call this the (endogenous) threshold effect. The two movements have opposite effects on the tax rate

\footnotetext{
${ }^{10}$ As $\gamma$ increases, parents prefer fertility $(\gamma)$ over quality $(\gamma \theta)$ since since $\theta<1$.
} 
and equilibrium enrollment. The net effect depends on the quality of public education (defined as spending per student) relative to the private option.

Public education quality is low when few resources are available (low $\mu$ ) or when there are many children enrolled (high $\gamma$, i.e. high fertility), corresponding to case 2 and 3.1 in Proposition 2 . Panel a in figure 1 shows this case. This implies a relatively large mass of rich households in the right tail choosing, in equilibrium, private education. An increase in $\mu$ further increases this mass, generating a large increase in the support for private education (the shape effect). It dominates the higher enrollment in public education by some middle income families caused by the threshold effect. Therefore the equilibrium tax and public enrollment decrease. However, the equilibrium spending per student can increase as the withdrawal of rich households from public education frees some resources.

Panel $b$ in figure 1 shows the case when the tax base $(\mu)$ is high or fertility preference $(\gamma)$ is low (regimes 1 and 3.2 in Proposition 2). In this case, the public education resources are high, so only the very rich households prefer private education. Thus, when the tax base increases, the shape effect generates a more modest boost of demand for private education than in the case above. Again, the threshold effect implies borderline households choose public education when average income increases marginally. However, the threshold effect dominates the shape effect in this case. Increased support for public education generates higher enrollment and taxes. Nonetheless, equilibrium spending per student can decrease if the increase in enrollment outpaces that in revenues.

\subsection{A mean preserving spread}

Next, we analyze the relationship between public policies and inequality - proxied by $\sigma$, the standard deviation of the income distribution. We perform a mean-preserving spread and study its implications on equilibrium public spending per student $q^{*}$, the tax rate $\tau^{*}$, and the enrollment in public schools $N^{*}$. Taking the derivative of $q^{*}$ with respect to $\sigma$ while keeping $\mu$ constant yields:

$$
\frac{\partial q^{*}}{\partial \sigma}=\frac{\phi \theta \mu}{\{1+\gamma \theta[1-d(\mu, \sigma)]\}^{2}} \frac{\partial d(\mu, \sigma)}{\partial \sigma},
$$

where $d(\mu, \sigma)=\left[y_{l}(\mu, \sigma) / \widetilde{y}(\mu, \sigma)\right]^{\alpha(\mu, \sigma)}$. Also,

$$
\begin{aligned}
\frac{\partial N^{*}}{\partial \sigma} & =\frac{1-\theta}{\left[(1-\theta)+\theta \Psi^{*}\right]^{2}} \frac{\partial \Psi^{*}}{\partial \sigma}=-\frac{1-\theta}{\left[(1-\theta)+\theta \Psi^{*}\right]^{2}} \frac{\phi \mu}{\gamma\left(q^{*}\right)^{2}} \frac{\partial q^{*}}{\partial \sigma} \\
\frac{\partial \tau^{*}}{\partial \sigma} & =\gamma \theta \frac{\partial \Psi^{*}}{\partial \sigma} .
\end{aligned}
$$

Thus, $\operatorname{sign}\left(\partial \tau^{*} / \partial \sigma\right)=\operatorname{sign}\left(\partial \Psi^{*} / \partial \sigma\right)=\operatorname{sign}\left(\partial N^{*} / \partial \sigma\right)=-\operatorname{sign}\left(\partial q^{*} / \partial \sigma\right)$. Next, we study the properties of functions $\partial q^{*} / \partial \sigma, \partial N^{*} / \partial \sigma$, and $\partial \tau^{*} / \partial \sigma$. The results are summa- 
rized in the following proposition:

Proposition 3. Let $\underline{\gamma}=[(2 /(\delta e))-1] /\left\{\theta\left[1-e^{-2}\right]\right\}$ and $\bar{\gamma}=[(1 / \delta)-1] /\{\theta[1-(1 / e)]\}$, where $e$ is the Euler's constant.

1) If $\gamma \leqslant \underline{\gamma}$, then $\partial \tau^{*} / \partial \sigma<0, \partial N^{*} / \partial \sigma<0, \partial q^{*} / \partial \sigma>0$

2) If $\gamma \geqslant \bar{\gamma}$, then $\partial \tau^{*} / \partial \sigma>0, \partial N^{*} / \partial \sigma>0, \partial q^{*} / \partial \sigma<0$;

3) If $\gamma \in(\underline{\gamma}, \bar{\gamma})$, then there exist a unique $\widehat{\mu} \in(0, \infty)$ such that

3.1) if $\mu \in(0, \widehat{\mu}]$, then $\partial \tau^{*} / \partial \sigma \geqslant 0, \partial N^{*} / \partial \sigma \geqslant 0, \partial q^{*} / \partial \sigma \leqslant 0$;

3.2) if $\mu \in(\widehat{\mu}, \infty)$, then $\partial \tau^{*} / \partial \sigma<0, \partial N^{*} / \partial \sigma<0, \partial q^{*} / \partial \sigma>0$;

(Proof in the Appendix).

The intuition of these results is the following. A mean preserving spread decreases the size of the middle class, adding mass to the tails of the income distribution (poor and rich households). This is the shape effect. Whether support for public education increases or not following this change in the shape of the distribution depends on the initial location of the indifference threshold. Moreover, the endogenous response of this threshold to higher inequality generates an additional effect.
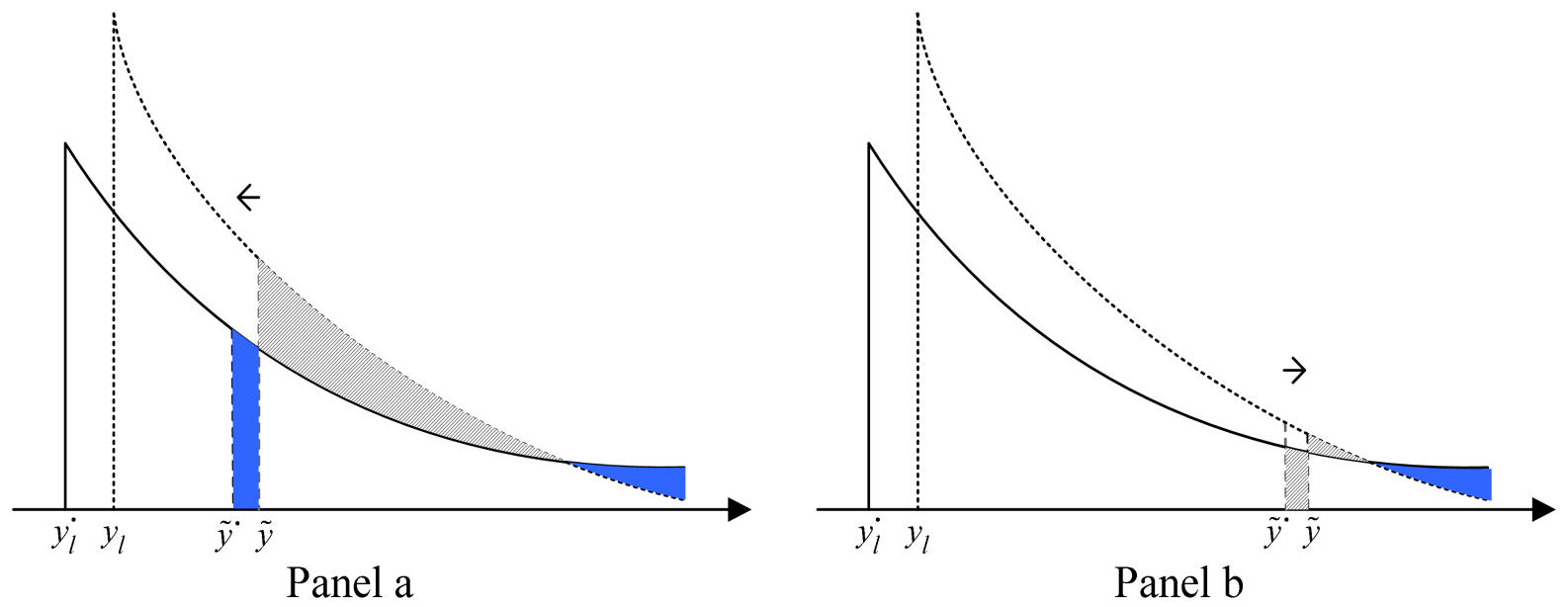

Figure 2: A mean preserving spread, indicated by dot variables (e.g. $\sigma^{\bullet}>\sigma$ ) and solid lines. Panel a: high fertility preference $(\gamma)$ or low tax base $(\mu)$. Panel b: low fertility preference or high tax base. The arrow indicates the endogenous change in the indifference threshold. Dark (light) shaded areas represent increases (decreases) in the support for private education.

Again, consider the case of low public education quality (low $\mu$ or high $\gamma$ ), corresponding to cases 2 and 3.1 in Proposition 3, and shown in panel a of figure 2. This implies that many rich and middle income households choose the private option. Thus, the indifference threshold lies relatively far from the right tail, in some middle income range. First, there are two opposing shape effects that arise under a mean preserving spread. On the one hand, the middle class shrinks and so does the support for private education. 
On the other hand, the mean preserving spread increases the mass of rich households in the right tail who send their children to private education. The overall effect on demand for public education thus depends on the relative magnitude of these opposing effects. Second, when public education is of low quality, an increase in inequality prompts the threshold households to switch to private education, as the mean preserving spread adds more poor, high fertility households in the left tail, which further reduce spending per student. This is the threshold effect. In this case, the negative effect on the demand for private education caused by the reduction of middle class dominates the positive effects stemming from the extra mass of rich households as well as the endogenous shift in the income threshold towards private schooling. As a result, the enrollment in public schools goes up and so does the tax rate. Despite the increase in revenues (and the extra resources made available by households who left public schools), spending per student is lower in equilibrium as middle income households (who were choosing lower fertility and private schooling before) have been replaced by low income and high fertility households that benefit from public education.

Conversely, when the tax base $(\mu)$ is large or fertility preference $(\gamma)$ is low, such as in cases 1 and 3.2 in Proposition 3 (panel $b$ of figure 2), the resources for public schooling are higher and, compared with the case above, the mass of middle income households that prefer private education is lower. Thus, the negative effect on the demand for private education generated by a reduction of middle income class is weaker and it is likely to be dominated by the positive effect generated by an increase in the mass of rich households (the shape effects). Second, there is again a threshold effect. In this case, the marginal households strictly prefer public education when inequality increases. Since the indifference threshold is far in the tail, the increase in demand for private education from the extra mass of rich households dominates, generating a decrease in public enrollment and the tax rate. In equilibrium, public school enrollment decreases faster than tax revenue, resulting in an increase in public spending per student.

To sum up, when inequality increases, the size of the poor and rich class increases at the expense of the middle class. When the tax base is low enough, the need for public education spending goes up steeply as a large share of mid income families choosing low fertility and private schooling are now replaced by high fertility low income families that choose public education. Thus, the relatively poorer households steer the political process in their favor, raising the tax rate. As the tax base is a constant share of the mean income, this increases the public spending per capita, or the size of redistribution. When the tax base is high, the interests of the rich households dominate as the shifts in fertility and education choices associated with the mean preserving spread are now weaker. Thus, the tax rate and the size of redistribution go down. Interestingly, the per student spending in public education, being driven by the endogenous response of enrollment, decreases in the first case and increases in the second. 


\section{Political power}

So far we have assumed that each household carries the same weight in the political process. Besides the obvious cases of authoritarian regimes or partially democratic countries, asymmetric distribution of political power can also arise in established democracies, for example when voter turnout varies systematically with demographic characteristics. ${ }^{11}$

In this section we use the benchmark model to implement and study a general, yet parsimonious political power function that assigns more clout to the rich. Next, we show that under fairly general conditions the equilibrium continues to be unique. Finally, we analyze the effects of uneven political representation on the public education budget, enrollment and spending per student.

To model the direct dependence between income and political power, we define

$$
p(y)=y^{\nu},
$$

where $y$ is the income level and $\nu>0$. The welfare function (15) becomes

$$
\begin{aligned}
W(\tau) & =\int_{y_{l}}^{\widetilde{y}}\left\{\ln \left[\frac{y}{(1+\gamma)(1+\tau)}\right]+\gamma \ln \left[\frac{\gamma}{\phi(1+\gamma)}\right]+\gamma \theta \ln (q)\right\} p(y) f(y) d y+ \\
& \int_{\widetilde{y}}^{\infty}\left\{\ln \left[\frac{y}{(1+\gamma)(1+\tau)}\right]+\gamma \ln \left[\frac{\gamma(1-\theta)}{\phi(1+\gamma)}\right]+\gamma \theta \ln \left[\frac{\phi \theta y}{1-\theta}\right]\right\} p(y) f(y) d y .
\end{aligned}
$$

Then, using (26) and retaining the relevant terms simplifies the expression to

$$
W(\tau)=-\ln (1+\tau)+\gamma \theta \Psi^{p} \ln (q) .
$$

where $\Psi^{p}=1-\left(y_{l} / \widetilde{y}\right)^{\alpha-\nu}$. In the following we assume $\alpha>\nu$, so that $\Psi^{p}$ is interior.

Notice that the only difference relative to (16), the aggregate welfare in the benchmark model, is the weight assigned to public education spending, which here is $\Psi^{p}$ rather than $\Psi=1-\left(y_{l} / \widetilde{y}\right)^{\alpha}$. It is easy to see that $\Psi^{p}<\Psi$. Thus, when political power is directly proportional to income, the interests of the rich (lower taxes) have a higher weight in the aggregate welfare. Since they are using mostly private education, the social welfare function reflects the new political balance by assigning a lower weight to public education provision.

The definition of equilibrium is similar to that in the benchmark model. The optimal tax rate is

$$
\tau^{p}=\gamma \theta \Psi^{p}
$$

while the private education income threshold is given by

\footnotetext{
${ }^{11}$ See e.g. Verba et al. (1995), Rosenstone and Hansen (1993), Morlan (1984), Hajnal and Lewis (2003).
} 


$$
\widetilde{y}=\frac{\mu}{\delta} \frac{1}{\Psi} \frac{\Psi^{p}}{1+\gamma \theta \Psi^{p}}
$$

Proposition 4. Let $\underline{\gamma}^{p}=\left(e^{-\ln (1 / 2)-\ln \delta}-1\right) / \theta$. If $\gamma>\underline{\gamma}^{p}$, there exists a unique equilibrium income threshold $\widetilde{y}^{*} \in\left(y_{l}, \infty\right)$ that solves equation (28), $\forall \nu>0$. Moreover, uniqueness is ensured $\forall \gamma>0$, for sufficiently small $\nu$. (Proof in the Appendix)

In the benchmark model, higher public education enrollment translates into higher tax revenues as the tax rate increases with the propensity to choose public education and the tax base stays constant. However, now the chosen tax rate reflects the taste of rich households for private education. In the following we study how the main results in the previous section change when we allow for political power.

Notice that the political power specification (26) is a monotonic and continuous function of income. Furthermore, as $\nu \rightarrow 0$, the income weights in the social welfare function vanish, yielding the benchmark model. Thus, in the limit, the results derived in Propositions 2 and 3 continue to hold.

Moreover, (26) provides a tractable way of determining the parameter $\nu$ based on the income level and the propensity to vote. Thus, knowing that the income groups $y_{l}$ and $y_{h}$ have propensities to vote $p_{l}$ and $p_{h}$ respectively, $\nu=\ln \left(p_{h} / p_{l}\right) / \ln \left(y_{h} / y_{l}\right)$. According to the 2006 Voter and Registration Supplement of the Current Population Survey, only 20.8\% of those with income under $10 K$ voted while among those with income from $\$ 100 K$ to $\$ 150 K$ the turnout was of $60.9 \%$. Using the midpoints of the two income brackets together with the respective turnout figures yields $\nu=0.33$. Similar calculations with 2008 data yield $\nu=0.18$.

For illustration, we replicate the exercises in Propositions 2 and 3 with and without political power. We use $\nu=0.26, \phi=0.075, \theta=0.4$ and $\gamma=2.7$ in the benchmark model, corresponding to the case of intermediate fertility rates (case 3$){ }^{12}$

Figure 3 graphs the three policy variables - public school enrollment, public spending per capita and the tax rate - as functions of the average income per capita, keeping dispersion constant. The thin lines represent the benchmark model and the thick lines the model with political power.

As expected, adding income correlated political weights lowers the tax rates at all income levels. However, lower taxation determines some households to switch to private education and thus enrollment in public schools also declines. Thus, public spending per student declines much less than revenues. Besides these level effects, political power induces tax rates to strictly increase with the mean income. In the benchmark model the tax rates follow a U-shaped pattern as a function of mean income for intermediate values of $\gamma$.

\footnotetext{
${ }^{12}$ Simulation results assuming extreme preferences (case 1 and 2) are included in Appendix B.
} 
Figure 3: Tax base effects
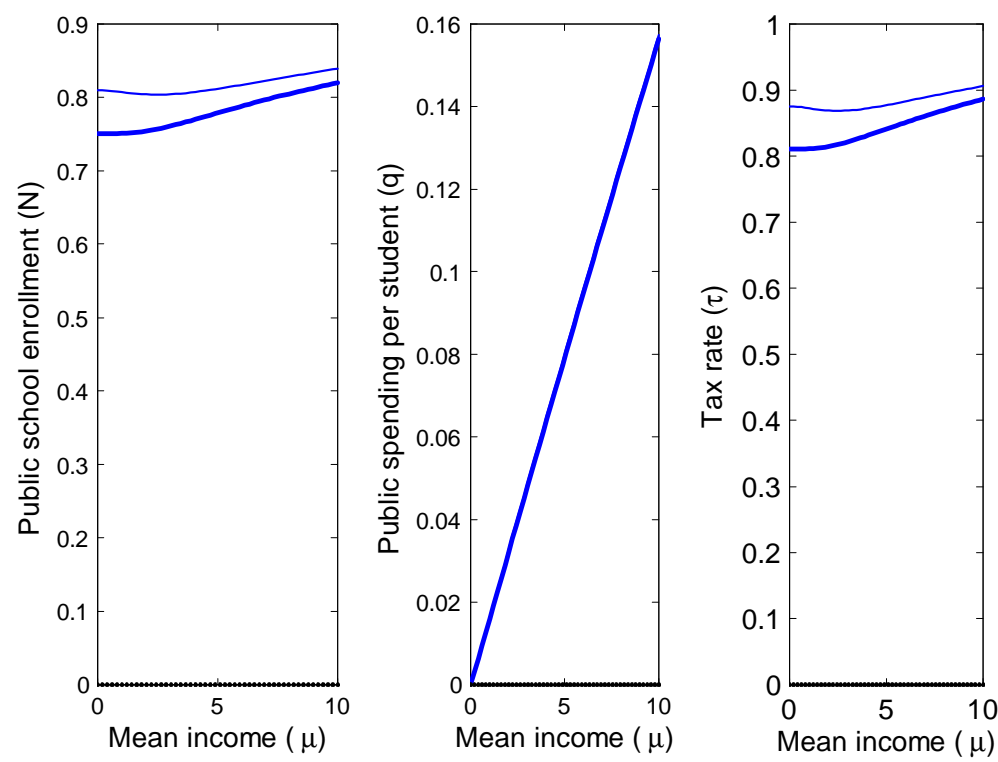

Main education variables as a function of the mean income (tax base), keeping dispersion constant, under political power $(\nu=0.26$, thick line) versus benchmark $(\nu=0$, thin line).

The thin lines in figure 4 display, from left to right, changes in the main variables, for a range of mean incomes when the standard deviation of the distribution increases by $10 \%$. Thus, in the leftmost panel, public school enrollment increases with inequality in poor economies but declines in more unequal rich countries, as already shown in Proposition 3. Then, we allow for political power. The thick lines depict similar changes when inequality increases. Rich households now have more power in setting the tax rate, such that higher inequality leads to lower tax rates in all countries as well as more abrupt declines in spending per student in low income economies. Case 3 in Proposition 3 shows that for intermediate values of the altruism coefficient $\gamma$, the equilibrium tax rate increases with inequality in poor economies, where the welfare of the relatively more numerous disadvantaged households depends on the quality of public schooling. This effect is overturned by allowing richer households to enjoy political power.

We have shown that augmenting the model to include political power preserves the uniqueness of the politico-economic equilibrium under fairly general conditions and induces the tax rate and the public spending per student to decrease more strongly with inequality. Moreover, while comparative statics results in the benchmark model are preserved for small asymmetries in political power $(\nu \rightarrow 0)$, for values of $\nu$ consistent with observed turnout levels by income categories, the tax rate can decrease with inequality irrespective of the average income in the economy. ${ }^{13}$

\footnotetext{
${ }^{13}$ One can show that $\partial \tau^{*} / \partial \sigma<0, \forall \mu>0$ for $\nu$ large enough.
} 
Figure 4: Effects of a mean preserving spread
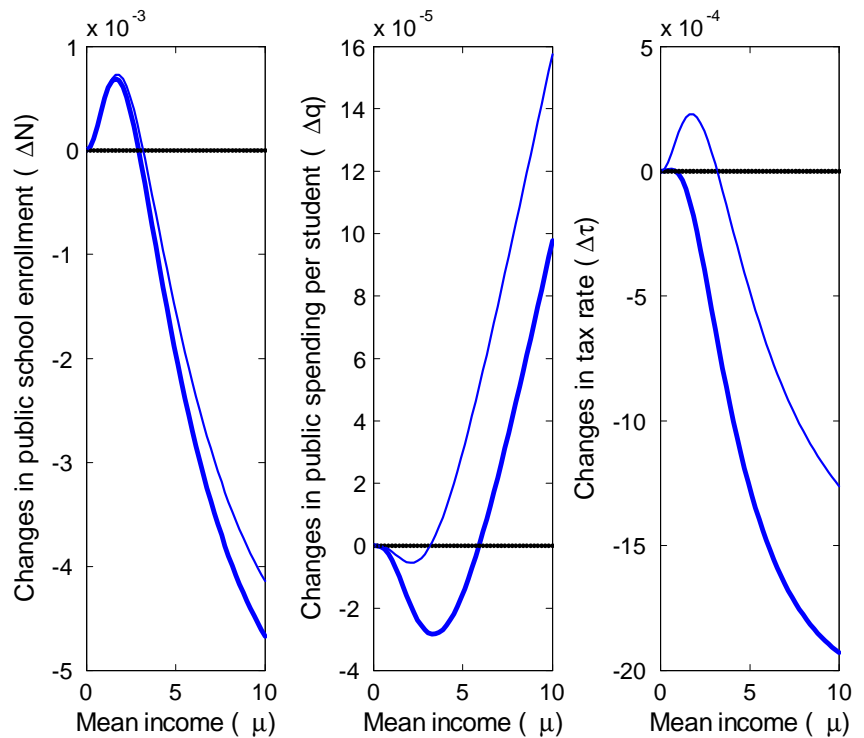

Changes in the main education variables from a 10 percent increase in income dispersion, for a given mean income, under political power $(\nu=0.26$, thick line) versus benchmark $(\nu=0$, thin line).

\section{Conclusion}

We have analyzed the role of inequality in the determination of public education spending in a voting model with opting out and endogenous fertility. We show that modelling household income heterogeneity to be consistent with the skewness of empirical income distributions has important consequences for the qualitative properties of the political equilibrium. We find a non-monotonic relationship between inequality and per student public spending, depending on 1) the preference for fertility relative to children quality and 2) the average per capita income (the tax base) in the economy. For moderate fertility preferences, we show that a mean preserving spread decreases public spending per student but increases tax rates and public school enrollments when the average income per capita is low, while it has opposite effects in richer economies. A marginal increase in the tax base, holding income dispersion constant, also yields non-monotonic effects. Extending the benchmark model to include income dependent political power reveals that higher inequality can lower tax rates independently of the average income in the economy. This could exacerbate the decrease in public spending per student in poor economies.

These results question the conventional wisdom regarding the redistributive role of public education, an important pillar of the modern welfare state. While this paper focuses on the political economy of education spending, optimal policies under opting out deserve further attention. On a more general note, our research suggests the relationship between income inequality and redistribution depends critically on the nature of the redistributive policy at hand, and in particular on the type of adjustments that can be 
expected from private agents in response to this policy. A careful assessment of these endogenous responses in other spheres of public policy is a potentially fruitful research avenue.

\section{References}

Alesina, A., R. Baqir, and W. Easterly (1999). Public Goods And Ethnic Divisions. The Quarterly Journal of Economics 114(4), 1243-1284.

Alesina, A., E. Glaeser, and B. Sacerdote (2001). Why Doesn't the US Have a EuropeanStyle Welfare System? Brookings Papers on Economic Activity (2), 187-277.

Baicker, K., J. Clemens, and M. Singhal (2012). The rise of the states: U.s. fiscal decentralization in the postwar period. Journal of Public Economics 96, 1079Ü1091.

Bearse, P., G. Glomm, and B. Ravikumar (2001). Education Finance in a Dynamic Tiebout Economy. Mimeo.

Bénabou, R. (1994). Human capital, inequality, and growth: A local perspective. European Economic Review 38(3-4), 817-826.

Bénabou, R. (1996). Heterogeneity, Stratification, and Growth: Macroeconomic Implications of Community Structure and School Finance. American Economic Review 86(3), 584-609.

Bénabou, R. (1997). Inequality and Growth. NBER Working Papers.

Bénabou, R. (2000). Unequal Societies: Income Distribution and the Social Contract. American Economic Review 90(1), 96-129.

Boustan, L., F. Ferreira, H. Winkler, and E. M. Zolt (2010). Inequality and Local Government: Evidence from U.S. Cities and School Districts, 1970-2000. Law and Economics Workshop, Berkeley Program in Law and Economics, UC Berkeley.

Cutler, D. M., E. L. Glaeser, and J. L. Vigdor (1999). The Rise and Decline of the American Ghetto. Journal of Political Economy 107(3), 455-506.

de la Croix, D. and M. Doepke (2009). To Segregate or to Integrate: Education Politics and Democracy. Review of Economic Studies 76(2), 597-628.

Dottori, D. and I.-L. Shen (2009, October). Low skilled immigration and the expansion of private schools. Temi di discussione (Economic working papers) 726, Bank of Italy, Economic Research Department.

Epple, D., R. Filimon, and T. Romer (1993). Existence of Voting and Housing equilibrium in a System of Communities with Property Taxes. Regional Science and Urban Economics 23(5), 585-610.

Epple, D. and G. J. Platt (1998). Equilibrium and Local Redistribution in an Urban Economy when Households Differ in both Preferences and Incomes. Journal of Urban Economics 43(1), 23-51. 
Fernandez, R. and G. Levy (2008). Diversity and redistribution. Journal of Public Economics 92(5-6), 925-943.

Fernandez, R. and R. Rogerson (1996). Income Distribution, Communities, and the Quality of Public Education. The Quarterly Journal of Economics 111(1), 135-64.

Glomm, G. (2004). Inequality, Majority Voting And The Redistributive Effects Of Public Education Funding. Pacific Economic Review 9(2), 93-101.

Goldin, C. and L. F. Katz (1997). Why the United States Led in Education: Lessons from Secondary School Expansion, 1910 to 1940. NBER Working Papers.

Gradstein, M., M. Justman, and V. Meier (2005). The Political Economy of Education: Implications for Growth and Inequality. CESifo Book Series. MIT.

Hajnal, Z. L. and P. G. Lewis (2003). Municipal Institutions and Voter Turnout in Local Elections. Urban Affairs Review 38(5), 645-668.

Lee, W. and J. E. Roemer (1998). Income Distribution, Redistributive Politics, and Economic Growth. Journal of Economic Growth 3(3), 217-240.

Lindert, P. H. (1996). What Limits Social Spending? Explorations in Economic History $33(1), 1-34$.

Luttmer, E. F. P. (2001). Group Loyalty and the Taste for Redistribution. Journal of Political Economy 109(3), 500-528.

Meltzer, A. H. and S. F. Richard (1981). A Rational Theory of the Size of Government. The Journal of Political Economy 89(5), 914-927.

Morlan, R. L. (1984). Municipal versus national election voter turnout: Europe and the United States. Political Science Quarterly 99, 457-470.

Perotti, R. (1996). Growth, Income Distribution, and Democracy: What the Data Say. Journal of Economic Growth 1(2), 149-87.

Persson, T. and G. Tabellini (1994). Is Inequality Harmful for Growth? American Economic Review 84(3), 600-621.

Persson, T. and G. Tabellini (2002). Political Economics: Explaining Economic Policy. MIT Press Books. The MIT Press.

Rhode, P. W. and K. S. Strumpf (2003). Assessing the Importance of Tiebout Sorting: Local Heterogeneity from 1850 to 1990. The American Economic Review 93(5), 16481677.

Rosenstone, S. J. and J. M. Hansen (1993). Mobilization, Participation, and Democracy in America. New York: Macmillan Publishing Company.

Soares, J. (1998). Altruism and Self-interest in a Political Economy of Public Education. IGIER working paper, Bocconi University.

Verba, S., S. K. Lehman, and H. E. Brady (1995). Voice and Equality: Civic Voluntarism in American Politics. Cambridge, Mass.: Harvard University Press. 


\section{Appendix A}

Proof of Proposition 1. The LHS of equation (19) is continuous and increasing in $\widetilde{y}$, while the $R H S$ is continuous and decreasing in $\widetilde{y}$. Moreover, $\lim _{\widetilde{y} \rightarrow \infty} L H S(\widetilde{y})=\infty>$ $\lim _{\widetilde{y} \rightarrow \infty} \operatorname{RHS}(\widetilde{y})=\mu /[\delta(1+\gamma \theta)]$. Next, $\operatorname{RHS}\left(y_{l}\right)=\mu / \delta=\alpha y_{l} /[\delta(\alpha-1)]>\operatorname{LHS}\left(y_{l}\right)=y_{l}$. By the Intermediate Value Theorem, the solution of equation (19) is interior and unique.

Proof of Proposition 2. Equation (23) implies that $\operatorname{sign}\left(\partial N^{*} / \partial \mu\right)=\operatorname{sign}\left(q^{*}-\right.$ $\left.\mu\left(\partial q^{*} / \partial \mu\right)\right)$.

The first steps of the proof develop the results needed to find an expression for $q^{*}-$ $\mu\left(\partial q^{*} / \partial \mu\right)$ that can be signed.

Recall $d(\mu, \sigma)=\left[y_{l}(\mu, \sigma) / \widetilde{y}(\mu, \sigma)\right]^{\alpha(\mu, \sigma)}$ and

$$
q^{*}=\frac{\phi \theta \mu}{1+\gamma \theta(1-d)} .
$$

Next, we get $\partial q^{*} / \partial \mu$ :

$$
\begin{aligned}
& \frac{\partial q^{*}}{\partial \mu}=\frac{\left(q^{*}\right)^{2}}{\phi \mu}\left\{\frac{\phi}{q^{*}}+\gamma \frac{\partial d(\mu, \sigma)}{\partial \mu}\right\} . \\
\frac{\partial d(\mu, \sigma)}{\partial \mu}= & d(\mu, \sigma)\left[\frac{\partial \alpha}{\partial \mu} \ln \left(\frac{y_{l}}{\widetilde{y}^{*}}\right)+\alpha \frac{\widetilde{y}^{*}}{y_{l}} \frac{\frac{\partial y_{l}}{\partial \mu} \widetilde{y}^{*}-y_{l} \frac{\partial \widetilde{y}^{*}}{\partial \mu}}{\left(\widetilde{y}^{*}\right)^{2}}\right] \\
= & d\left[\frac{\partial \alpha}{\partial \mu} \ln \left(\frac{y_{l}}{\widetilde{y}^{*}}\right)+\frac{\alpha}{y_{l}} \frac{\partial y_{l}}{\partial \mu}\right]-d \frac{\alpha}{\widetilde{y}^{*}} \frac{\partial \widetilde{y}^{*}}{\partial \mu} .
\end{aligned}
$$

We use (1) to write $y_{l}$ and $\alpha$ as functions of the first two moments, $\mu$ and $\sigma$ :

$$
y_{l}(\mu, \sigma)=\frac{\alpha(\mu, \sigma)-1}{\alpha(\mu, \sigma)} \mu, \text { and } \alpha(\mu, \sigma)=1+\sqrt{1+\frac{\mu^{2}}{\sigma^{2}}} .
$$

We use (A.5) to find $\partial y_{l} / \partial \mu$ :

$$
\frac{\partial y_{l}}{\partial \mu}=\frac{\alpha-1}{\alpha}+\frac{\mu}{\alpha^{2}} \frac{\partial \alpha}{\partial \mu}
$$

where

$$
\frac{\partial \alpha}{\partial \mu}=\left(1+\frac{\mu^{2}}{\sigma^{2}}\right)^{-1 / 2} \frac{\mu}{\sigma^{2}}>0
$$

Using (A.6) and

$$
\frac{1}{\widetilde{y}^{*}} \frac{\partial \widetilde{y}^{*}}{\partial \mu}=\frac{\partial q^{*}}{\partial \mu} \frac{1}{q^{*}}
$$


in (A.4), we obtain:

$$
\frac{\partial d(\mu, \sigma)}{\partial \mu}=d\left[\frac{\partial \alpha}{\partial \mu} \ln \left(\frac{y_{l}}{\widetilde{y}^{*}}\right)+\frac{\alpha-1}{y_{l}}+\frac{\mu}{\alpha y_{l}} \frac{\partial \alpha}{\partial \mu}\right]-d \frac{\alpha}{q^{*}} \frac{\partial q^{*}}{\partial \mu} .
$$

We use (A.9) in (A.2) and $y_{l}=(\alpha-1) \mu / \alpha$. Rearranging terms, we get:

$$
\frac{\partial q^{*}}{\partial \mu}\left(1+d \frac{\alpha \gamma}{\phi} \frac{q^{*}}{\mu}\right)=\frac{q^{*}}{\mu}+\frac{\alpha \gamma}{\phi} \frac{\left(q^{*}\right)^{2}}{\mu^{2}} d+\frac{\left(q^{*}\right)^{2}}{\phi \mu} \gamma d \frac{\partial \alpha}{\partial \mu} \underbrace{\left[\ln \left(\frac{y_{l}}{\widetilde{y}^{*}}\right)+\frac{\mu}{\alpha y_{l}}\right]}_{\omega(\mu, \sigma)} .
$$

We use $(\mathrm{A} .10)$ and $y_{l}=(\alpha-1) \mu / \alpha$ to compute $q^{*}-\mu\left(\partial q^{*} / \partial \mu\right)$. We obtain:

$$
q^{*}-\mu \frac{\partial q^{*}}{\partial \mu}=-\frac{\gamma d \frac{\left(q^{*}\right)^{2}}{\phi \mu} \frac{\partial \alpha}{\partial \mu}\left[\ln \left(\frac{y_{l}}{\widetilde{y}^{*}}\right)+\frac{\mu}{\alpha y_{l}}\right]}{1+d \frac{\alpha \gamma}{\phi} \frac{q^{*}}{\mu}} .
$$

Denote by $\omega(\mu, \sigma)=\ln \left(y_{l} / \widetilde{y}^{*}\right)+\mu /\left(\alpha y_{l}\right)$. As $\partial \alpha / \partial \mu>0, \operatorname{sign}\left(q^{*}-\mu\left(\partial q^{*} / \partial \mu\right)\right)=$ $-\operatorname{sign}(\omega(\mu, \sigma)) \Longrightarrow \operatorname{sign}\left(\partial N^{*} / \partial \mu\right)=-\operatorname{sign}(\omega(\mu, \sigma))$.

Next, we study the $\operatorname{sign}(\omega(\mu, \sigma))$. From the expression of $\omega(\mu, \sigma)$ we see that $\omega(\mu, \sigma) \geqslant$ $0 \Longleftrightarrow \mu /\left(\alpha y_{l}\right) \geqslant \ln \left(\widetilde{y}^{*} / y_{l}\right) \Longleftrightarrow \widetilde{y}^{*} \leqslant \widehat{y}$, where $\widehat{y}=y_{l} e^{\mu /\left(\alpha y_{l}\right)}$.

Using the expressions for $y_{l}$ and $\alpha$ from (A.5), we can express $\widehat{y}$ as a function of the first two moments of the income distribution, $\mu$ and $\sigma$ :

$$
\widehat{y}(\mu, \sigma)=\mu \frac{z}{z+1} e^{1 / z},
$$

where $z=\sqrt{1+\mu^{2} / \sigma^{2}}$ and $e$ is the Euler's constant.

In order to see if $\widetilde{y}^{*} \leqslant \widehat{y}$ holds, we evaluate the $L H S$ and $R H S$ of equation (19) at $\widehat{y}$. The $L H S$ is increasing in $\widetilde{y}$, while the $R H S$ is decreasing in $\widetilde{y}$. Thus, the inequality $\widetilde{y}^{*} \leqslant \widehat{y}$ holds if $\operatorname{LHS}(\widehat{y}(\mu, \sigma)) \geqslant \operatorname{RHS}(\widehat{y}(\mu, \sigma))$, or

$$
\underbrace{\delta \frac{z}{z+1} e^{1 / z}}_{h(\mu)} \geqslant \underbrace{\frac{1}{1+\gamma \theta\left[1-e^{-(1+z) / z}\right]}}_{v(\mu)} .
$$

Notice that the inequality implies a restriction in $\mu$ and $\sigma$. In the following, we study the properties of functions $h(\mu, \sigma)$ and $v(\mu, \sigma)$.

$$
\begin{aligned}
\frac{\partial h}{\partial \mu} & =\left(1+\frac{\mu^{2}}{\sigma^{2}}\right)^{-1 / 2} \frac{\mu}{\sigma^{2}}\left[\delta \frac{e^{1 / z}}{(z+1)^{2}}-\delta \frac{z e^{1 / z}}{z+1} z^{-2}\right] \\
& =-\left(1+\frac{\mu^{2}}{\sigma^{2}}\right)^{-1 / 2} \frac{\mu}{\sigma^{2}} \frac{\delta e^{1 / z}}{z(z+1)^{2}}<0 \\
\frac{\partial v}{\partial \mu} & =\frac{e^{-(1+z) / z}}{\left\{1+\gamma \theta\left[1-e^{-(1+z) / z}\right]\right\}^{2}} \frac{1}{z^{2}}\left(1+\frac{\mu^{2}}{\sigma^{2}}\right)^{-1 / 2} \frac{\mu}{\sigma^{2}}>0
\end{aligned}
$$


Consequently, $h(\mu)$ is decreasing and $v(\mu)$ is increasing in $\mu \in(0, \infty)$. Both functions are continuous. In addition, $\lim _{\mu \rightarrow 0} h(\mu)=\delta e / 2, \lim _{\mu \rightarrow 0} v(\mu)=1 /\left[1+\gamma \theta\left(1-e^{-2}\right)\right], \lim _{\mu \rightarrow \infty} h(\mu)=\delta$, and $\lim _{\mu \rightarrow \infty} v(\mu)=1 /\{1+\gamma \theta[1-(1 / e)]\}$.

We distinguish three cases:

1) $\lim _{\mu \rightarrow 0} v(\mu) \geqslant \lim _{\mu \rightarrow 0} h(\mu) \Longleftrightarrow 1 /\left[1+\gamma \theta\left(1-e^{-2}\right)\right] \geqslant \delta e / 2 \Longleftrightarrow \gamma \leqslant \underline{\gamma}=[2 /(\delta e)-1] /[\theta(1-$ $\left.e^{-2}\right)$; In this case $h(\mu)<v(\mu)$ for any $\mu \in(0, \infty) \Longrightarrow \widetilde{y}^{*}>\widehat{y} \Longrightarrow \omega(\mu)<0 \Longrightarrow$ $\partial N^{*} / \partial \mu>0$

2) $\lim _{\mu \rightarrow \infty} v(\mu) \leqslant \lim _{\mu \rightarrow \infty} h(\mu) \Longleftrightarrow \gamma \geqslant \bar{\gamma}=[(1 / \delta)-1] /\{\theta[1-(1 / e)]\}$; In this case $h(\mu)>$ $v(\mu)$ for any $\mu \in(0, \infty) \Longrightarrow \widetilde{y}^{*}<\widehat{y} \Longrightarrow \omega(\mu)>0 \Longrightarrow \partial N^{*} / \partial \mu<0$;

3) $\left\{\begin{array}{c}\lim _{\mu \rightarrow 0} v(\mu)<\lim _{\mu \rightarrow 0} h(\mu) \\ \lim _{\mu \rightarrow \infty} v(\mu)>\lim _{\mu \rightarrow \infty} h(\mu)\end{array} \Longleftrightarrow\left\{\begin{array}{l}\gamma>\underline{\gamma}=[(2 /(\delta e))-1] /\left[\theta\left(1-e^{-2}\right)\right] \\ \gamma<\bar{\gamma}=[(1 / \delta)-1] /\{\theta[1-(1 / e)]\}\end{array}\right.\right.$

In this case, by the Intermediate Value Theorem, the two function intersect once in $\widehat{\mu} \in(0, \infty)$. There are two subcases here:

3.1) $\mu \in(0, \widehat{\mu}] \Longrightarrow h(\mu) \geqslant v(\mu) \Longrightarrow \widetilde{y}^{*} \leqslant \widehat{y} \Longrightarrow \omega(\mu) \geqslant 0 \Longrightarrow \partial N^{*} / \partial \mu \leqslant 0$;

3.2) $\mu \in(\widehat{\mu}, \infty) \Longrightarrow h(\mu)<v(\mu) \Longrightarrow \widetilde{y}^{*}>\widehat{y} \Longrightarrow \omega(\mu)<0 \Longrightarrow \partial N^{*} / \partial \mu>0$.

Proof of Corollary 1. We use equation (A.10). As $\partial \alpha / \partial \mu>0$, if $\omega(\mu, \sigma)>0$ then $\partial q^{*} / \partial \mu>0$. As established in Proposition 2, $\omega(\mu, \sigma)>0$ when $\gamma \geqslant \bar{\gamma}$ or when $\gamma \in(\underline{\gamma}, \bar{\gamma})$ and $\mu \in(0, \widehat{\mu})$.

Consider the case when $\gamma \in(\underline{\gamma}, \bar{\gamma})$. As the $R H S$ of equation (A.10) contains some other positive terms in addition to $\omega(\mu, \sigma) \Longrightarrow$ there exists $\widetilde{\mu}>\widehat{\mu}$ such that $\partial q^{*} / \partial \mu>0$ on the interval $\mu \in(0, \widetilde{\mu})$.

Proof of Proposition 3. Equation (25) implies that $\operatorname{sign}\left(\partial q^{*} / \partial \sigma\right)=\operatorname{sign}(\partial d(\sigma) / \partial \sigma)$.

Taking the derivative of $d(\sigma)=\left[\mathbf{y}_{l}(\boldsymbol{\sigma}) / \widetilde{y}(\boldsymbol{\sigma})\right]^{\alpha(\sigma)}$ with respect to $\sigma$ we get:

$$
\begin{aligned}
\frac{\partial d(\sigma)}{\partial \sigma} & =d(\sigma)\left[\frac{\partial \alpha}{\partial \sigma} \ln \left(\frac{y_{l}}{\widetilde{y}^{*}}\right)+\alpha \frac{\widetilde{y}^{*}}{y_{l}} \frac{\frac{\partial y_{l}}{\partial \sigma} \widetilde{y}^{*}-y_{l} \frac{\partial \widetilde{y}^{*}}{\partial \sigma}}{\left(\widetilde{y}^{*}\right)^{2}}\right] \\
& =d(\sigma)\left[\frac{\partial \alpha}{\partial \sigma} \ln \left(\frac{y_{l}}{\widetilde{y}^{*}}\right)+\frac{\alpha}{y_{l}} \frac{\partial y_{l}}{\partial \sigma}\right]-d(\sigma) \frac{\alpha}{\widetilde{y}^{*}} \frac{\partial \widetilde{y}^{*}}{\partial \sigma} .
\end{aligned}
$$

Next, we calculate $\partial \widetilde{y}^{*} / \partial \sigma=\left(\partial q^{*} / \partial \sigma\right) / \phi \theta \delta, \partial \alpha / \partial \sigma=-\left(\mu^{2} / \sigma^{3}\right)\left[1+(\mu / \sigma)^{2}\right]^{-1 / 2}<0$, $\partial y_{l} / \partial \sigma=\left(\mu / \alpha^{2}\right)(\partial \alpha / \partial \sigma)<0$. We use (A.17) in the expression of $\left(\partial q^{*} / \partial \sigma\right),(25)$, and group terms to obtain:

$$
\frac{\partial q^{*}}{\partial \sigma} \underbrace{\left\{1+\frac{\mu d(\sigma)}{1+\gamma \theta[1-d(\sigma)]^{2}} \frac{\alpha}{\delta} \frac{1}{\widetilde{y}^{*}}\right\}}_{+}=\underbrace{\frac{\phi \theta \mu d(\sigma)}{1+\gamma \theta[1-d(\sigma)]^{2}}}_{+} \underbrace{\frac{\partial \alpha}{\partial \sigma}}_{-} \underbrace{\left[\ln \left(\frac{y_{l}}{\widetilde{y}^{*}}\right)+\frac{\mu}{\alpha y_{l}}\right]}_{\omega(\mu, \sigma)} .
$$

From the expression above we can see that $\operatorname{sign}\left(\partial q^{*} / \partial \sigma\right)=-\operatorname{sign}(\omega(\mu, \sigma))$. Also, $\operatorname{sign}\left(\partial N^{*} / \partial \sigma\right)=\operatorname{sign}\left(\partial \tau^{*} / \partial \sigma\right)=\operatorname{sign}(\omega(\mu, \sigma))$. 
We studied the properties of the function $\omega(\mu, \sigma)$ in the proof of Proposition 2. Thus, there are three cases:

1) $\gamma \leqslant \underline{\gamma}=\left[(2 /(\delta e)-1] /\left[\theta\left(1-e^{-2}\right] \Longrightarrow \omega(\mu)<0 \Longrightarrow \partial \tau^{*} / \partial \sigma<0, \partial N^{*} / \partial \sigma<\right.\right.$ $0, \partial q^{*} / \partial \sigma>0$

2) $\gamma \geqslant \bar{\gamma}=[(1 / \delta)-1] /\{\theta[1-(1 / e)]\} \Longrightarrow \omega(\mu)>0 \Longrightarrow \partial \tau^{*} / \partial \sigma>0, \partial N^{*} / \partial \sigma>$ $0, \partial q^{*} / \partial \sigma<0$

3) $\gamma \in(\underline{\gamma}, \bar{\gamma})$. There are two subcases here:

3.1) $\mu \in(0, \widehat{\mu}] \Longrightarrow \omega(\mu) \geqslant 0 \Longrightarrow \partial \tau^{*} / \partial \sigma \geqslant 0, \partial N^{*} / \partial \sigma \geqslant 0, \partial q^{*} / \partial \sigma \leqslant 0$;

3.2) $\mu \in(\widehat{\mu}, \infty) \Longrightarrow \omega(\mu)<0 \Longrightarrow \partial \tau^{*} / \partial \sigma<0, \partial N^{*} / \partial \sigma<0, \partial q^{*} / \partial \sigma>0$.

Proof of Proposition 4. Denote $z=\left(y_{l} / \widetilde{y}\right) \in(0,1]$. Then, the equilibrium enrollment is determined by

$$
\frac{y_{l}}{z}=\frac{\mu}{\delta} \frac{1}{1-z^{\alpha}} \frac{1-z^{\alpha-\nu}}{1+\gamma \theta\left(1-z^{\alpha-\nu}\right)}
$$

Denote the left and the right hand sides of (A.19) with LHS and RHS respectively. It is easy to verify that $\lim _{z \rightarrow 0} L H S=+\infty$ and $\lim _{z \rightarrow 1} L H S=y_{l}, \lim _{z \rightarrow 0} R H S=$ $\mu /(\delta(1+\gamma \theta))$. Using l'Hospital rule,

$$
\lim _{z \rightarrow 1} R H S=\frac{\mu}{\delta} \frac{-(\alpha-\nu) z^{\alpha-\nu-1}}{-z^{\alpha-\nu-1}\left[\alpha z^{\nu}\left(1+\gamma \theta\left(1-z^{\alpha-\nu}\right)\right)+\left(1-z^{\alpha}\right) \gamma \theta(\alpha-\nu)\right]}
$$

or $\lim _{z \rightarrow 1} R H S=\mu(\alpha-\nu) /(\delta \alpha)$. Clearly, LHS is monotonically decreasing in $z$. The RHS can be first decreasing and then increasing in $z$ since

$$
\frac{\partial R H S}{\partial z}>0 \Leftrightarrow \frac{1-z^{\alpha-\nu}}{1-z^{\alpha}} z^{\nu}\left(1-\frac{\gamma \theta}{1+\gamma \theta} z^{\alpha-\nu}\right)>\frac{\alpha-\nu}{\alpha(1+\gamma \theta)}
$$

and since $\left(1-z^{\alpha-\nu}\right)\left(1-\gamma \theta /(1+\gamma \theta) z^{\alpha-\nu}\right) /\left(1-z^{\alpha}\right)>1, \forall z \in(0,1]$, a sufficient condition for $\partial R H S / \partial z>0$ is $z>((\alpha-\nu) /(\alpha(1+\gamma \theta)))^{1 / \nu}$. (i) Thus a sufficient condition for uniqueness is

$$
R H S_{z=0}<L H S_{z=1} \Leftrightarrow \mu /(\delta(1+\gamma \theta))<y_{l}
$$

If furthermore $R H S_{z=1}>L H S_{z=1} \Leftrightarrow \mu(\alpha-\nu) /(\delta \alpha)>y_{l} \Leftrightarrow \nu<\alpha-(\alpha-1) \delta / \alpha$, the equilibrium enrollment is interior, otherwise $z=1\left(\widetilde{y}^{*}=y_{l}\right)$. Using the definition of $\delta$ and (A.5) in (A.20) and solving for $\gamma$ results in $\gamma>\left(\alpha /\left((\alpha-1)(1-\theta)^{1 / \theta-1}\right)-1\right) / \theta>0$. Thus, if household's concern for children is high enough, there is a unique equilibrium threshold for private enrollment.

(ii) Intuitively, as $\nu$ goes to zero, the problem is reduced to the benchmark, which has a unique equilibrium. Since $\partial L H S / \partial z<0$, imposing $\partial R H S / \partial z>0$ guarantees uniqueness. This condition can be further rewritten as

$\left(1-z^{\alpha-\nu}\right)\left[\alpha z^{\nu}\left(1+\gamma \theta\left(1-z^{\alpha-\nu}\right)\right)+\gamma \theta\left(1-z^{\alpha}\right)(\alpha-\nu)\right]>(\alpha-\nu)\left(1-z^{\alpha}\right)\left(1+\gamma \theta\left(1-z^{\alpha-\nu}\right)\right)$. 
The inequality holds for any $z<1$ as $\nu \rightarrow 0$.

\section{Appendix B}


Figure 5: Simulation results using a log-normal income distribution.
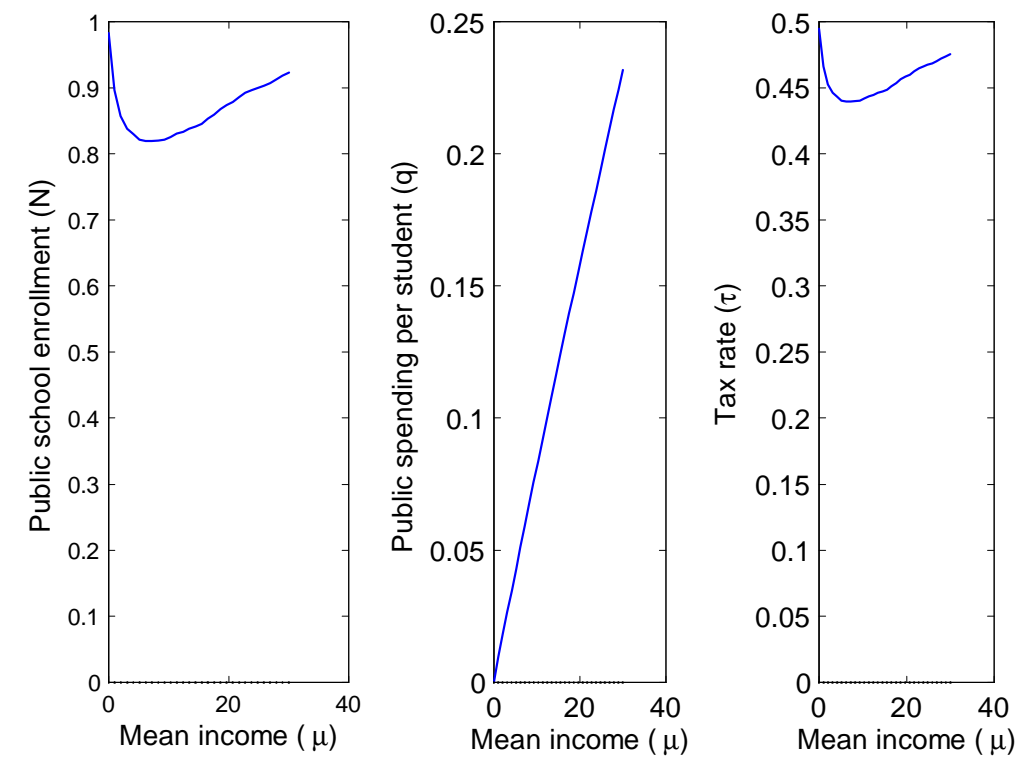

(a) Tax base effects
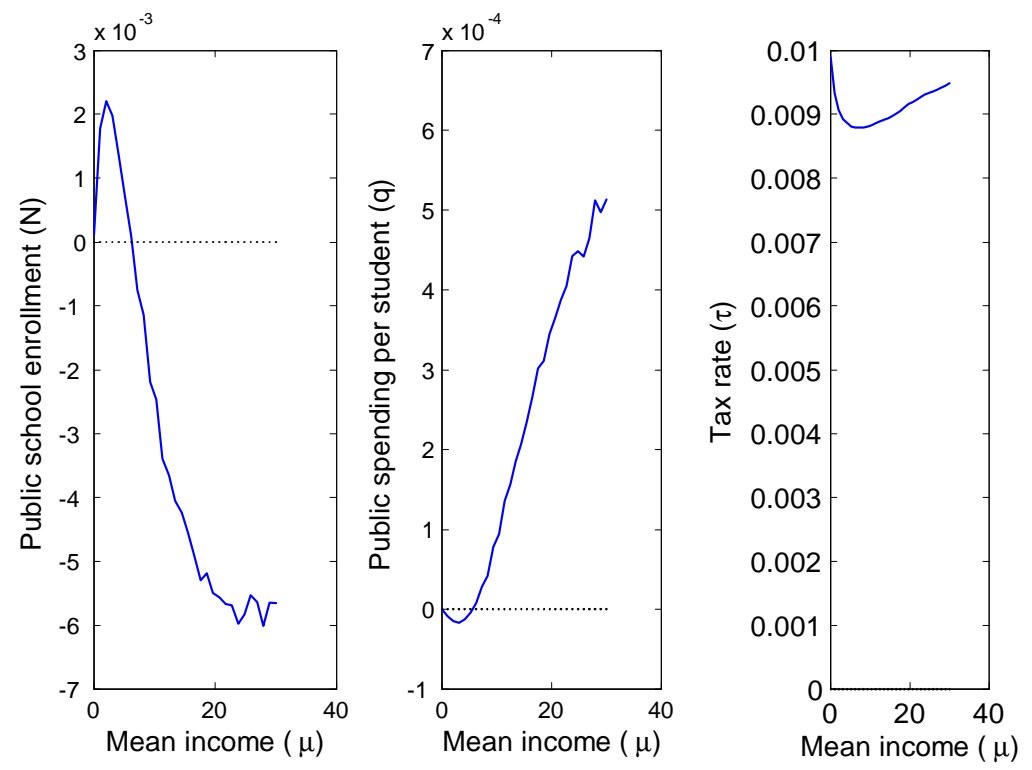

(b) Mean Preserving Spread

Main education variables as a function of the mean income, keeping dispersion constant (panel a) and Changes in main variables in response to a 10 percent increase in dispersion, at each level of mean income (panel b). $\theta=0.2, \phi=0.025, \gamma=5$. The benchmark income standard deviation is set at 27 . 
Figure 6: Low preference for fertility: $\gamma \leqslant \underline{\gamma}$
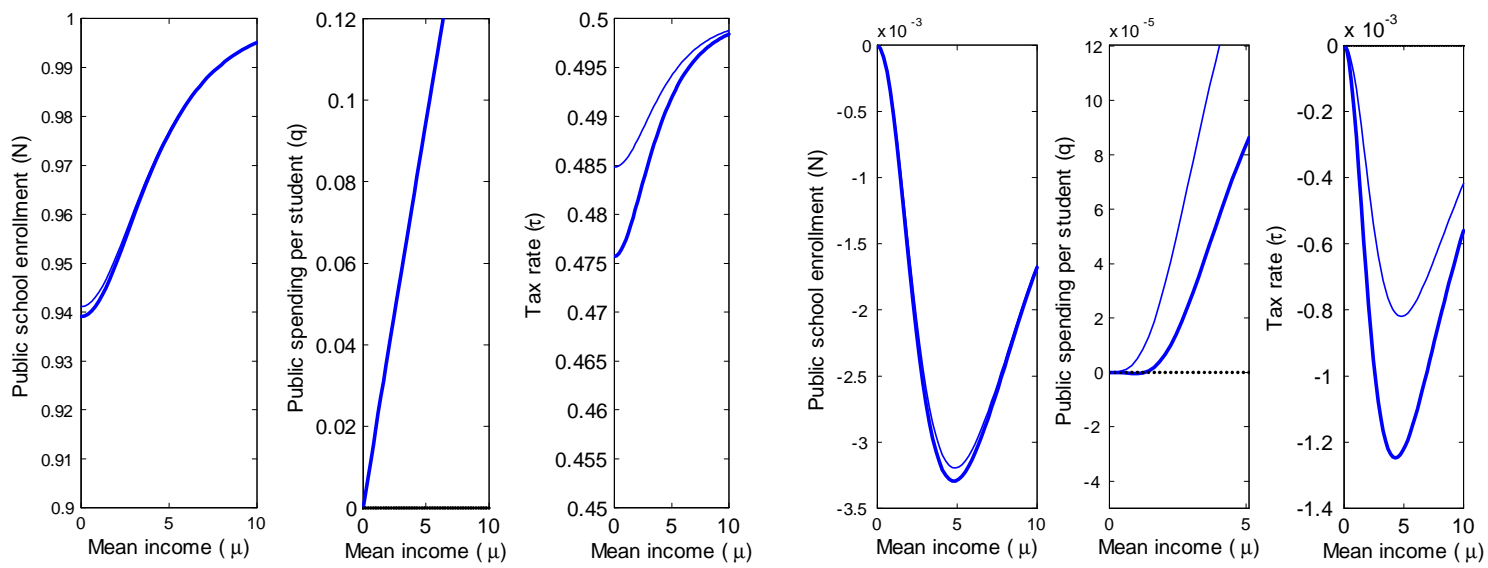

(a) Tax base effects

(b) Mean Preserving Spread

Main education variables as a function of the mean income, keeping dispersion constant (panel a) and Changes in main variables in response to a 10 percent increase in dispersion, at each level of mean income (panel b) under political power $(\nu=0.26$, thick line) versus benchmark $(\nu=0$, thin line). $\theta=0.4, \gamma=1$.

Figure 7: High preference for fertility: $\gamma \geqslant \bar{\gamma}$
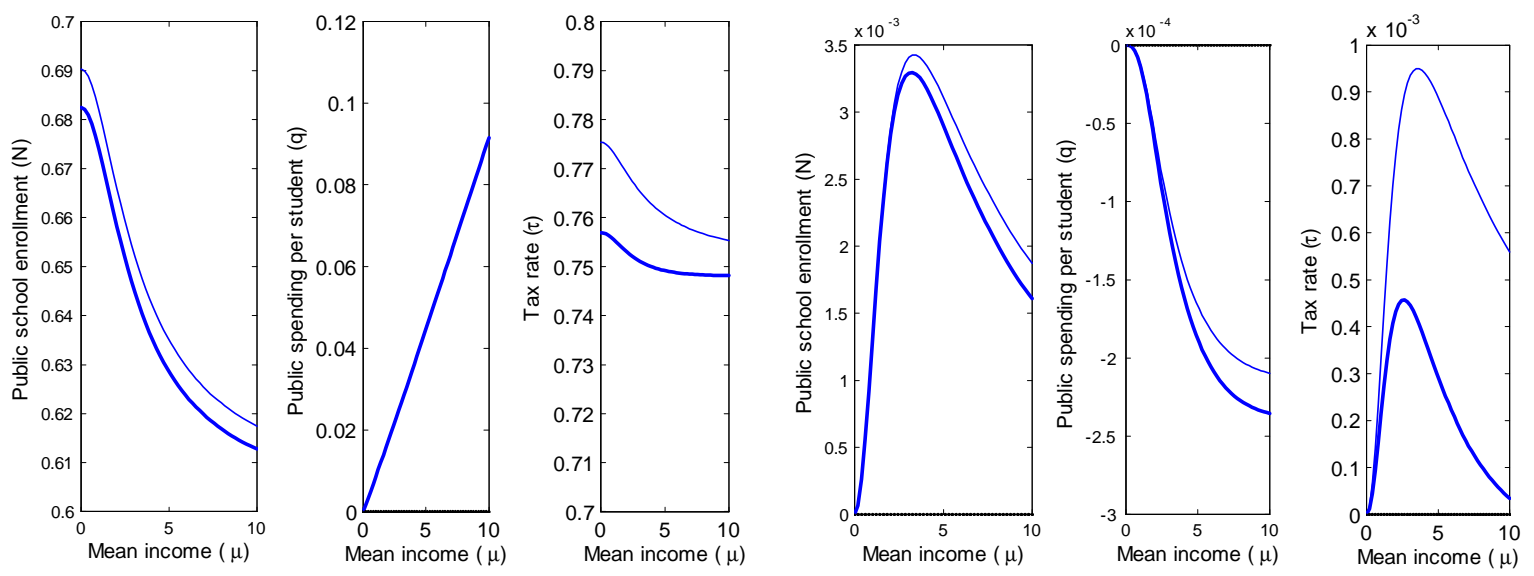

(a) Tax base effects

(b) Mean Preserving Spread

Main education variables as a function of the mean income, keeping dispersion constant (panel a) and Changes in main variables in response to a 10 percent increase in dispersion, at each level of mean income (panel b) under political power $(\nu=0.26$, thick line) versus benchmark $(\nu=0$, thin line). $\theta=0.4, \gamma=6$. 